\title{
Numerical simulation of urban heat island intensity under urban-suburban surface and reference site in Kolkata, India
}

\author{
Ansar Khan ${ }^{1} \cdot$ Soumendu Chatterjee ${ }^{2}$
}

Received: 27 January 2016/Accepted: 18 March 2016/Published online: 9 April 2016

(C) Springer International Publishing Switzerland 2016

\begin{abstract}
Urban heat island intensity (UHII) in Kolkata has been assessed using simplified numerical model for vertical temperature measurement in tropical monsoon summer month (June, 2015) during pre-onset of monsoon season. The data of 25 field observation sites show that the surface temperature curves are likely to mathematical trapeziums, and surface temperatures are related to vertical air temperatures. Therefore, approximated temperature trapeziums that are determined by high and lower air temperatures can be used to numerical simulation the vertical surface temperature fluctuation or variation. Two different field observation sites respectively in the urban and suburban areas were taken as model purpose. Distinct and good agreement was obtained between numerical simulation and observed temperature. Observed temperatures indicate the mean temperature under urban concrete surface environment is about $3.54{ }^{\circ} \mathrm{C}$ greater than that of adjacent suburban open surface. The deviation from normal is due to the heat wave environmental effect and different surface thermal effect, which are about $2.08{ }^{\circ} \mathrm{C}$ and $2.92{ }^{\circ} \mathrm{C}$, respectively. Combined with air relative humidity $(\mathrm{RH})$, 'Heat' islands associated with 'Dry' island, which means urban air relative humidity is lower than suburban air relative humidity $(79.52 \%$,). According to the variation of $R H$ and temperature deviation graphs, urban heat island, vertical surface types and rainfall are important factors that influence the air humidity and temperature.
\end{abstract}

Ansar Khan

khanansargeo@gmail.com

1 Department of Geography and Environment Management, Vidyasagar University, Midnapore, India

2 Department of Geography, Presidency University, Kolkata, India
Keywords Vertical temperature - Numerical simulation . Urban heat island intensity (UHII) - Temperature trapeziums · Urban concrete surface $\cdot$ Suburban open surface

\section{Introduction}

Researchers are being carried out world-wide to understand the nature of temperature change during recent past at different geographical scales so that comprehensive inferences can be drawn about recent temperature trend and future urban climate (Chatterjee et al. 2013; Khan et al. 2014; Bisai et al. 2014a). The urban heat island (UHI) effect is the phenomenon that a metropolis is usually significantly warmer than its rural surroundings. It occurs because city centre buildings and street surface materials, which have high heat capacities, store heat during the day, and release heat slowly at night. The adverse energy and environmental effects of UHIs, and methods to alleviate them, has become a major research topic in sustainability programs. Decreasing the energy consumption of buildings is an important topic in environmental engineering (Wang and Akbari 2014). An urban area with lower albedo absorbs more than $80 \%$ of the solar energy that increases their air temperature compared to rural areas (Touchaei and Wang 2015). In the community scale UHI is close to the urban surface, surface temperatures have an indirect, but significant influence on air temperatures and urban thermal comfort. Daytime solar energy absorption is the primary cause of the urban heat island effect in summer. Pavements and roofs comprise over $60 \%$ of urban surfaces. Dark materials, dark pavements and roofs, absorb $80-90 \%$ of sunlight. Lighter materials, white roofs and lighter colored pavements, absorb only $30-65 \%$ of sunlight. There is an 
interaction of thermal radiation between roof, wall and ground surfaces. The use of reflective building surface materials is a critical solution for UHI mitigation (Akbari et al. 1997; Berdahl and Bretz 1994; Bretz and Akbari 1997; Bretz et al. 1998; Konopacki and Akbari 2001; Synnefa et al. 2006, 2007; Taha et al. 1988). Along with urban centres of developed nations, the phenomenon is now prevalent in many Asian cities as well (Santamouris 2015).Temperature variation impacts on the engineering properties of urban surface, and consequently changes the strength and stability of various engineered structures. Many previous studies show that the increase of shallow soil temperature influences soil permeability, suction of unsaturated soils, and soils shear strength etc. (Jacinto et al. 2009; Tang and Cui 2005). Vertical air temperature prediction therefore plays an important role in the research of issues related to environment, energy sources and engineering (Florides and Kalogirou 2007; Pouloupatis et al. 2011; Shi et al. 2008). The causes of UHI are not the same in different climates or city features. Therefore, many models and approaches, including observation and simulation techniques, have been proposed to understand the causes of UHI formation and to mitigate the corresponding effects (Huang et al. 2008a, b; Mirzaei and Haghighat 2010; Yao et al. 2011). Urban heat islands are studied through in situ experiments (Mohan et al. 2012, 2013; Ren et al. 2007; Kolokotroni et al. 2006; Stewart 2011), remote observations (Weng 2009, Yuan and Bauer 2007; Jin 2012), and numerical models. Numerical simulation of the urban heat island effect helps in increasing understanding of the phenomenon at region of interest, assessing major causative factors, and designing mitigation strategies. Over the years, numerical methods have evolved from simple energy budget model (Myrup 1969) to single and multilayer urban canopy models (Kusaka and Kimura 2004; Kondo et al. 2005). Huang et al. (2008a, b) investigated the diurnal changes of urban and rural air temperatures in four types of ground cover and urban heat island intensity. Their study indicates that the urban heat island intensity varies in time and on different surface types. However, surface temperatures, vertical air temperatures, and corresponding UHI effect are not involved. Continuous monitoring of vertical air temperature is expensive. Analytical methods and computer technologies can provide cheaper, alternative ways to predict the vertical air temperature. However, the vertical air temperature field is influenced by many factors, including solar radiation, air temperature, wind speed, rainfall, shelter, and air properties (Mihalakakou 2002). Most of these factors change irregularly and as a result, the prediction and estimation of vertical air temperature is multifaceted. In previous studies, many analytical models (Smerdon et al. 2006), semi-analytical models (Droulia et al. 2009; Yuan et al. 2008), empirical models (Al-Ajmi et al. 2006), numerical methods (Janssen et al. 2004; Rees et al. 2000), Fourier models (Graham et al. 2010) and neural network methods (dos Santos Coelho et al. 2009) have been used to solve various heat transfer problems (Rees et al. 2000). Most of these methods require many measured parameters, some of which are hard to obtain under real field conditions. On the basis of the relationship between air temperatures and surface temperatures, a simplified model is introduced to simulate the variation of vertical air soil temperatures during summer hot weather (Liu et al. 2011). The method has been used to estimate the vertical air temperature of urban concrete surface and sub urban open surfaces in two sites of Kolkata city. The simulated temperatures are compared with the observed data to investigate the influence factors of the urban heat island. Combined with the air humidity, the influences of UHI, surface types and precipiation-evapotransporation on the vertical air temperature and air humidity are analyzed. Further study attempts to explore the selection of reference site for determining urban heat island intensity and applicability for in situ and numerical-simulated data.

\section{In-situ characteristics of observation}

Kolkata $\left(22^{\circ} 57 \mathrm{~N}, 88^{\circ} 37 \mathrm{E}\right)$ is the capital city of the state of West Bengal and situated in one of the largest economics hub of the eastern India. The city's total geographical area is $185 \mathrm{~km}^{2}$ and urban population is over 14.1 million (Registrar General 2011). Seasons are distinct in city, with usually tropical savannah climate and tremendous temperature and rainfall during monsoon throughout year. The main purpose of the in situ temperature as well as humidity observation is to detect the diurnal variation of vertical air temperature and surface temperature with urban concrete surface and suburban open surface, so as to get the relationship between them. On the basis of relationship, the daily surface temperatures can be approximated by air temperature at peak 14:00 h and daily lowest temperatures. These data and the relationship are used to determine the top boundary temperatures in numerical simulation. Meanwhile, the air temperature, surface temperature, vertical temperatures and air moisture of two sites were recorded everyday during the study period in order to compare with simulation results.

\section{Temperature}

The month of June is characterized by falling daily high temperatures, with daily highs ranging from 36 to $33{ }^{\circ} \mathrm{C}$ over the course of the month, exceeding $38^{\circ} \mathrm{C}$ or dropping below $30{ }^{\circ} \mathrm{C}$ only one day in ten. Daily low temperatures are 


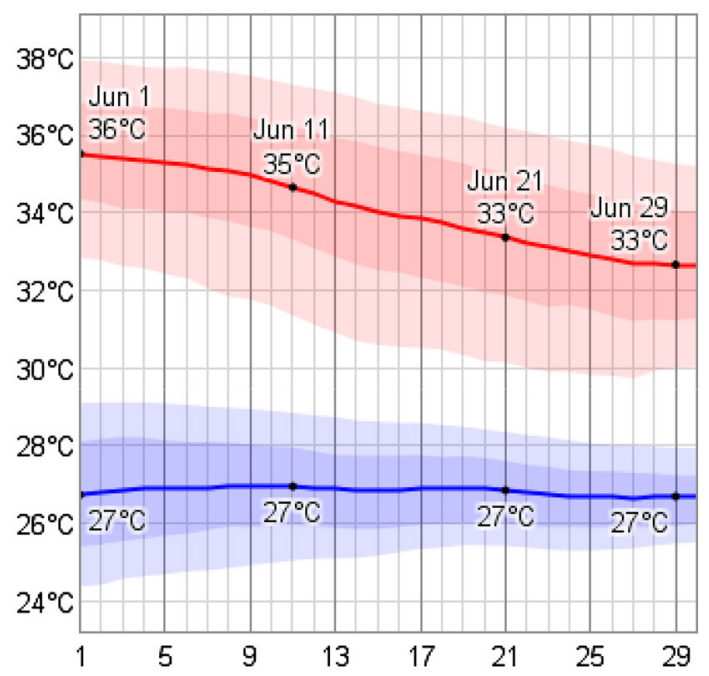

Fig. 1 The daily average low (blue) and high (red) temperature with percentile bands (inner band from 25th to 75 th percentile, outer band from 10th to 90 th percentile)

around $27^{\circ} \mathrm{C}$, falling below $24{ }^{\circ} \mathrm{C}$ or exceeding $29^{\circ} \mathrm{C}$ only one day in ten in Fig. 1.

\section{Humidity}

The relative humidity typically ranges from $58 \%$ (mildly humid) to $96 \%$ (very humid) over the course of a typical June, rarely dropping below $48 \%$ (comfortable) and reaching as high as $100 \%$ (very humid). The air is driest around June 1 , at which time the relative humidity drops below $62 \%$ (mildly humid) three days out of four; it is most humid around June 27, rising above $94 \%$ (very humid) 3 days out of four in Fig. 2.

\section{Precipitation}

The probability that precipitation observed at this location varies throughout the month. Precipitation is most likely around June 30, occurring in $74 \%$ of days. Precipitation is least likely around June 1, occurring in $56 \%$ of days. Throughout June, the most common forms of precipitation are thunderstorms, light rain, and moderate rain. Thunderstorms are the most severe precipitation observed during $58 \%$ of those days with precipitation. They are most likely around June 1, when it is observed during $39 \%$ of all days. Light rain is the most severe precipitation observed during $24 \%$ of those days with precipitation. It is most likely around June 30, when it is observed during $20 \%$ of all days. Moderate rain is the most severe precipitation observed during $17 \%$ of those days with precipitation. It is most likely around June 30 , when it is observed during $16 \%$ of all days in Fig. 3.

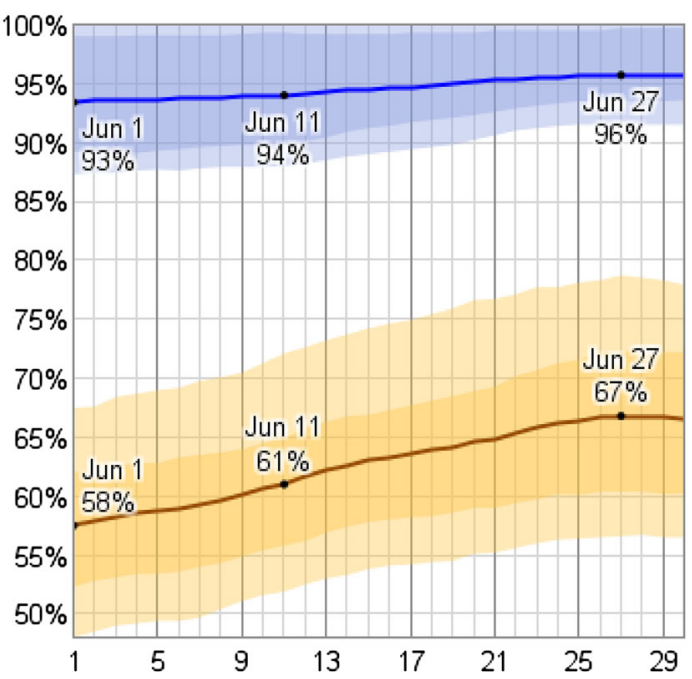

Fig. 2 The average daily high (blue) and low (brown) relative humidity with percentile bands (inner bands from 25th to 75th percentile, outer bands from 10th to 90th percentile)

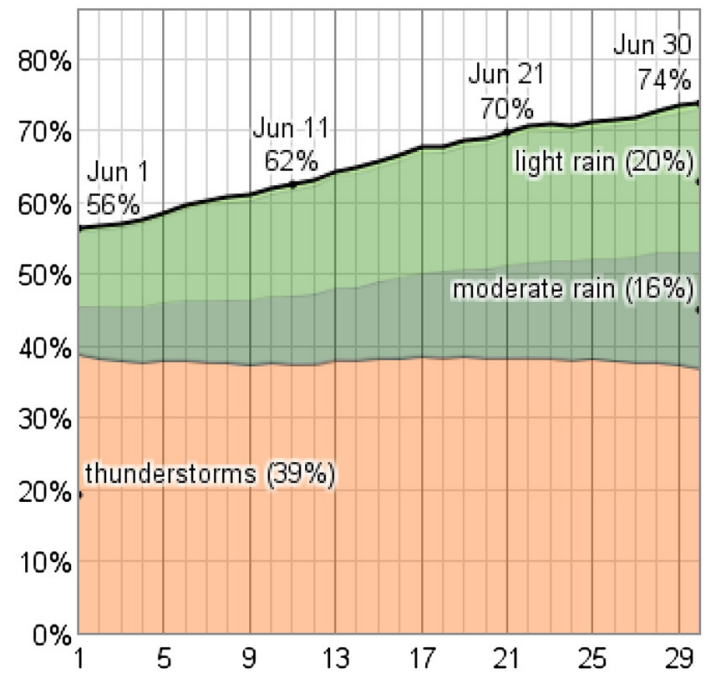

Fig. 3 The fraction of days in which various types of precipitation are observed. If more than one type of precipitation is reported in a given day, the more severe precipitation is counted. For example, if light rain is observed in the same day as a thunderstorm, that day counts towards the thunderstorm totals. The order of severity is from the top down in this graph, with the most severe at the bottom

\section{Hourly surface temperature observation}

In this study 25 observation sites were randomly set-up in the urban area, suburbs and other sites of Kolkata city (Table 1). The sites are located on open space without any shelter of physical environment, such as bare land. The temperature sensor was set-up on a pole at base above the reference ground surface. During recording time of temperature and humidity, wind speed less than $5 \mathrm{~m} / \mathrm{s}$ and wind direction was variable in direction. Then, temperature and humidity of 
Table 125 Observation sites randomly set-up in the urban area, suburbs and other sites of Kolkata city

\begin{tabular}{|c|c|c|c|c|c|}
\hline \multirow[t]{2}{*}{ Urban concrete surface } & \multicolumn{2}{|c|}{ Geographic coordinate } & \multirow[t]{2}{*}{ Urban open surface } & \multicolumn{2}{|c|}{ Geographic coordinate } \\
\hline & $\phi(N)$ & $\lambda(E)$ & & $\phi(N)$ & $\lambda(E)$ \\
\hline Alipore & 22.33 & 88.21 & Madhyagram & 22.69 & 88.46 \\
\hline Allen's Park & 22.54 & 88.05 & Rishra & 22.72 & 88.34 \\
\hline Park Circus & 22.54 & 88.36 & Shibpore & 22.56 & 88.27 \\
\hline Maidan & 22.54 & 88.34 & Thakurpukur & 22.45 & 88.28 \\
\hline Writers Building & 22.57 & 88.34 & Agarpara & 22.68 & 88.37 \\
\hline Behala & 22.51 & 88.03 & Barrackpore & 22.75 & 88.09 \\
\hline Dhakuria & 22.51 & 88.36 & Bantala & 22.52 & 88.44 \\
\hline Dumdum & 22.65 & 88.43 & Bantala Bypass & 22.50 & 88.51 \\
\hline Gouribari & 22.59 & 88.37 & Govindapur & 22.38 & 88.38 \\
\hline New Alipore & 22.50 & 88.33 & & & \\
\hline Jadavpur & 22.29 & 88.23 & & & \\
\hline Laldighi & 22.57 & 88.34 & & & \\
\hline Rajarhat & 22.61 & 88.46 & & & \\
\hline Shealdah & 22.56 & 88.36 & & & \\
\hline Sithi Crossing & 22.63 & 88.37 & & & \\
\hline Salt Lake & 22.57 & 88.44 & & & \\
\hline
\end{tabular}

urban concrete surface and suburban open surface were recorded simultaneously at the 25 observation sites.

The selected urban concrete surface temperature, urban open space temperature and vertical air temperature of a suburban site are plotted in Fig. 4. As shown in the Fig. 4, temperature begins to increase at $4: 00 \mathrm{~h}$; rise rapidly in the following 6:00 h and peak between 12:00 and 16:00 h, which is called the period of 'high temperature'. Afterward, temperature steadily turns down, lowering at the period of 'low temperature' ranging from 3:00 to 4:00 h of the next calendar day. Therefore, the diurnal surface temperature curves can be approximated by 'temperature

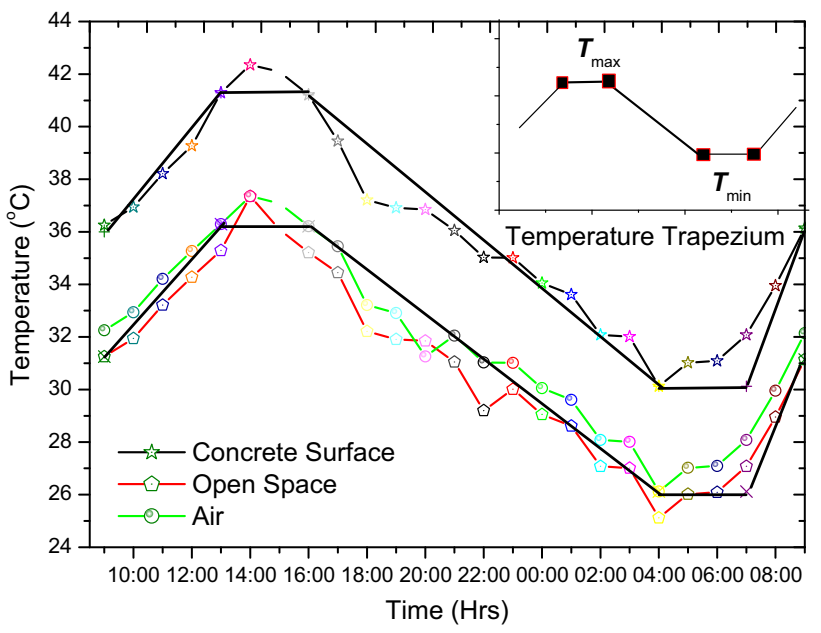

Fig. 4 Diurnal temperatures can be approximated by temperature trapezium, which is defined by maximum- $\left(T_{\max }\right)$ and minimum surface temperatures $\left(T_{\min }\right)$ trapeziums' (Fig. 5), which are defined by temperature gradient $\left(\mathrm{T}_{\max }\right.$ and $\left.\mathrm{T}_{\min }\right)$. Surface temperature can easily be calculated by vertical air temperature on the basis of the relationship between them (Mihalakakou 2002). According to hourly temperature data of 25 field observation sites, surface temperature and vertical air temperatures are correlated significantly at night time in Fig. 4.

Generally, urban open surface temperatures are average 1.5-3.4 ${ }^{\circ} \mathrm{C}$ greater than the vertical air temperatures during low temperature period. However, the surface temperature fluctuates considerably at noon time, in particular between 12:00 and 14:00 h. As shown in Table 2, average difference between vertical air temperature and surface temperate is greater on dry days (up to $4.5^{\circ} \mathrm{C}$ for urban concrete surface) and lower on rainy days (up to $3.2^{\circ} \mathrm{C}$ ). Therefore, average temperature should be used to establish the relationship between vertical air temperatures and surface temperatures.

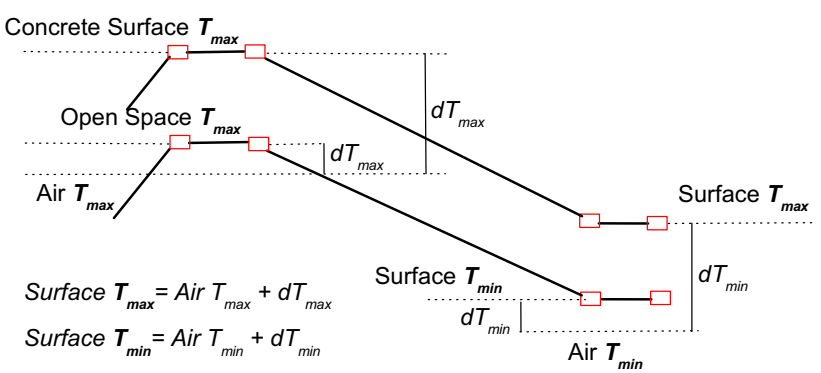

Fig. 5 Maximum and minimum surface temperatures can be calculated from the air temperatures, according to the relationship between them 
Table 2 Mean temperature of urban concrete surface, urban open space and vertical air for the month of June, 2015

\begin{tabular}{lllll}
\hline Urban concrete surface $\left({ }^{\circ} \mathrm{C}\right)$ & Urban open surface $\left({ }^{\circ} \mathrm{C}\right)$ & Vertical air temperature $\left({ }^{\circ} \mathrm{C}\right)$ & Time & Weather \\
\hline 41.2 & 37.8 & 37.3 & Sunny \\
40.1 & 37.1 & 36.9 & $12: 00$ & $13: 00$ \\
42.7 & 38.9 & 37.5 & $14: 00$ & Rainy \\
\hline
\end{tabular}

Vertical air temperatures were measured at $0.1 \mathrm{~m}$ above the ground surface

As shown in Fig. 4, the temperature trapeziums can be defined by $\mathrm{T}_{\max }$ and $\mathrm{T}_{\min }$ surface temperatures, which are determined by vertical air temperatures. And the relationship is expressed as follows:

$u(t)=F\left(A T_{\max }+d T_{\max }, A T_{\min }+d T_{\min , t} t\right)$

where $A T_{\max }$ is the high air temperature at $14: 00 \mathrm{~h}, A T_{\min }$ is the daily lowest air temperature; $d T_{\max }$ and $d T_{\min }$ are the corresponding average differences between surface temperatures and air temperatures; the function $\mathrm{F}$ creates a temperature trapezium according to the maximum- and minimum surface temperatures, then returns the temperature at the time t. The high air temperatures for soil surface and concrete surface were measured everyday at 14:00 $\mathrm{h}$ in the observation sites. And daily lowest air temperatures can be obtained from the India Meteorology Department (IMD), Kolkata. The diurnal temperature observation shows that $d T_{\max } 3.0{ }^{\circ} \mathrm{C}$ and $d T_{\min } 4.2{ }^{\circ} \mathrm{C}$ for the urban concrete surface, and $4.2{ }^{\circ} \mathrm{C}$ and $d T_{\min } 4.2^{\circ} \mathrm{C}$ for the suburban open surface.

\section{Profile of vertical air temperature}

A field campaign was conducted over the city region of Kolkata to quantify and analyze the urban heat island effect in Kolkata. Micrometeorological stations were set up at various sites throughout the Kolkata region for continuous measurement of air temperature and relative humidity. There were 25 locations in the field campaign numbered

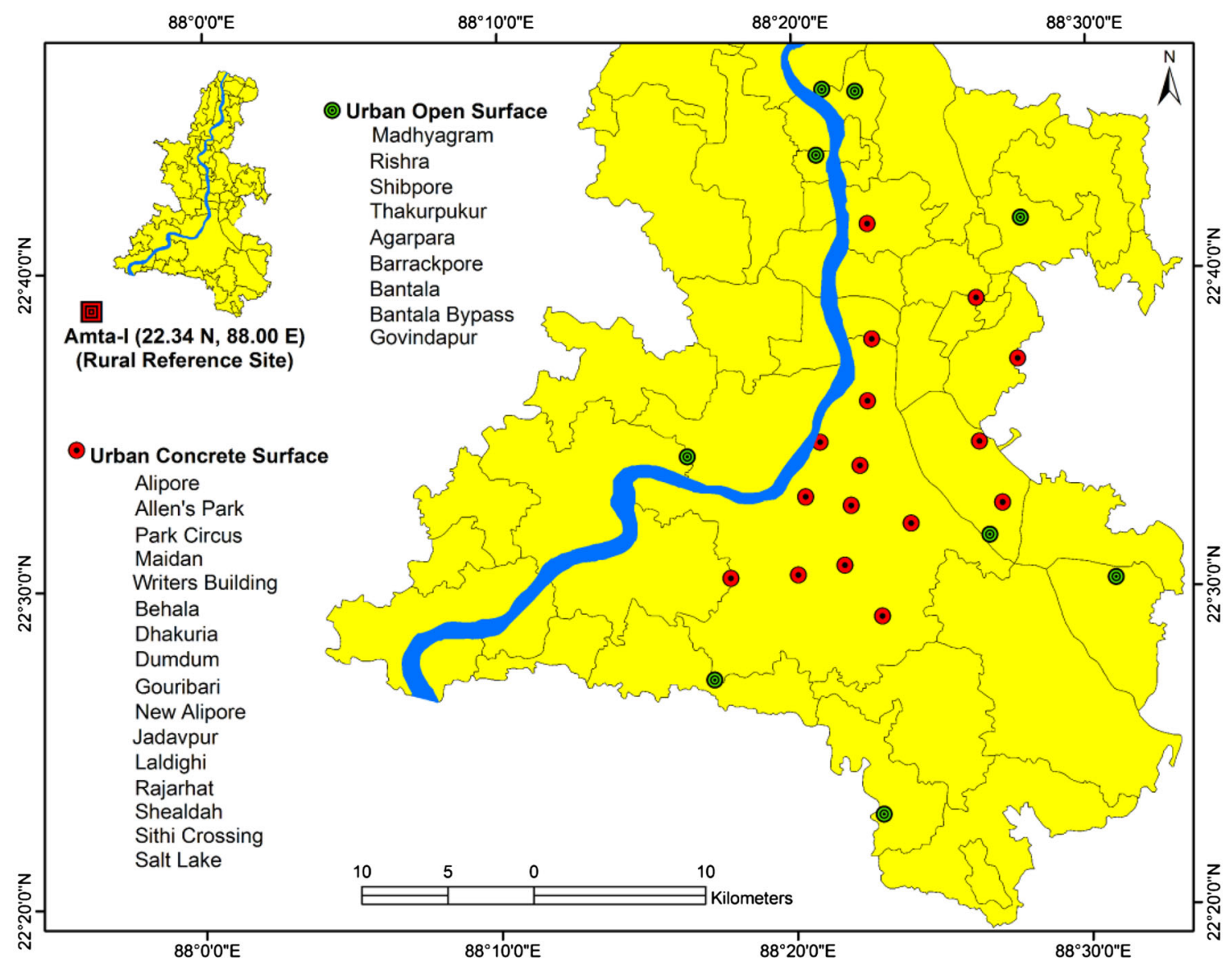

Fig. 6 Setup of micrometeorological stations in field campaign June, 2015 
from 1 to 25 where instruments were installed. Out of these 25 sites, 16 are with urban characteristics while 9 are suburban (Table 1, Fig. 6). The urban observation station is located in an open place near Behala $\left(22^{\circ} 51^{\prime} \mathrm{N}, 88^{\circ} 0.31^{\prime} \mathrm{E}\right)$, where the UHI intensity is known to be relatively high. In addition, a rural observation site (Amta, $22^{\circ} 34^{\prime} \mathrm{N}, 88^{\circ} 00^{\prime} \mathrm{E}$ ) located about $43 \mathrm{~km}$ from periphery of Kolkata city was chosen as reference site for computing urban heat island intensity. The rural site was a farmland free from any urban influence. Hereafter in the text, station names will be followed by their number in brackets. Measurements in this field campaign have been utilized as temperature in summer hot weather. Three sites out of these installed at height of 10-15 $\mathrm{m}$ for measuring other numerical model evaluation for the urban heat island assessment meteorological parameters for rainfall. Temperature sensors and air moisture sensors were installed at specific height in the reference point (Fig. 6). The temperature sensors are Pt100, with a precision of $\pm 0.1{ }^{\circ} \mathrm{C}$. They were set up in reference at height of $0.1,0.2,0.3,0.4,0.6,1,2,3,4$ and $5 \mathrm{~m}$, respectively. The humidity probe was used to measure the relative humidity at 9 different heights $(0.1,0.2,0.3$, $0.4,0.6,1,2,3,4$ and $5 \mathrm{~m}$ ). Its range is between 0 and 100 $(\%)$, with a precision of $\pm 0.01(\%)$. In order to record nearsurface air temperatures and humidity, a temperature-humidity sensor was fixed at the ground surface. Urban ground is generally covered with concrete and asphalt pavements, while suburban ground is mainly covered with bare land and grasses. Therefore, the changes of vertical air temperatures under an urban concrete surface and a suburban open soil surface act as representatives and are investigated. Figure $3 \mathrm{a}$ and $\mathrm{b}$ show the temperature data of the urban concrete- and suburban bare soil surfaces, respectively, for a period of 30 days beginning June 1, 2015 and ending June 30, 2015. According to historic daily temperature records, this period has the hottest days in Indian summer monsoon season as well as study area (IMD $2006 \&$ 2007). As shown in the figures, the temperatures fluctuate dramatically during the June month (onset of monsoon). Air and shallow vertical air temperatures were high in mid June, while lowering late June (on advent of rainy days). The temperature fluctuations reveal that the vertical air temperatures depend on urban surface environments and lower atmospheric compositions (Bisai et al. 2014b).

\section{Numerical simulation of observed temperature}

Vertical air temperatures are influenced by solar radiation, air moisture, wind speed, and environmental shelter, etc. Essentially, these factors act on the ground surface and then affect the vertical temperature field. In order to simulate the vertical temperature variations, we will make three assumptions (Liu et al. 2011): (1) the air is homogeneous, and as a result, heat only flows in vertical direction; (2) no surface heat source; (3) air moisture is not considered. Therefore, the corresponding heat conduction equation is one-dimensional. In the Cartesian coordinates, the one-dimensional transient heat conduction differential equation is as follows (positive direction is downward):

$$
\begin{aligned}
& \left\{\frac{\partial T}{\partial t}=\alpha \frac{\partial^{2} T}{\partial Z^{2}} \quad(0<z<L)\right. \\
& \alpha=\frac{k}{\rho c}
\end{aligned}
$$

where $T$ is temperature $\left({ }^{\circ} \mathrm{C}\right), t$ is time (s), $z$ is height $(\mathrm{m}), \alpha$ is thermal diffusivity $\left(\mathrm{ms}^{-2}\right), k$ is thermal conductivity (w/ $\mathrm{mK}), r$ is density $\left(\mathrm{g} / \mathrm{cm}^{3}\right), c$ is heat capacity $(\mathrm{J} / \mathrm{kg} \mathrm{K})$, and $L$ is the height of bottom boundary $(8 \mathrm{~m})$. The origin of the coordinates is attached to the ground surface. The related physical properties of urban open surface sand mixed soil and urban concrete surface are shown in Table 3.

Therefore, the differential equation can be solved when the top boundary temperature $\mu_{1}(t)$ and bottom boundary temperature $\mu_{2}(t)$ are given. Since surface temperature is influenced by many factors, it changes between different measured points on the same ground surface. The difference may be significant, especially on concrete surfaces. Although the problem is assumed to be one-dimensional, the Vertical temperatures are actually influenced by the whole ground surface. The error of the result may even larger if the temperatures of an arbitrary surface point are used in the simulation. However, near-surface air temperature indicates the surface temperature of the whole surface region. Therefore, the top boundary temperatures are calculated from air temperatures according to Eq. (1). The bottom boundary is the top of the constant temperature level, which is about $8 \mathrm{~m}$ in the Kolkata city area. The temperature of this level is generally equal to the historical average annual temperature. The

Table 3 Physical properties of urban concrete surface and urban open surface

\begin{tabular}{lllll}
\hline Material/surface & $\begin{array}{l}\text { Dry density } \\
\left(\mathrm{g} / \mathrm{cm}^{3}\right)\end{array}$ & $\begin{array}{l}\text { Thermal conductivity } \\
(\mathrm{w} / \mathrm{mK})\end{array}$ & $\begin{array}{l}\text { Heat capacity } \\
(\mathrm{kJ} / \mathrm{kg} \mathrm{C})\end{array}$ & $\begin{array}{l}\text { Thermal diffusivity } \\
\left(\times 10^{-6} \mathrm{~m}^{2} / \mathrm{s}\right)\end{array}$ \\
\hline Urban open surface (sand) & 1.52 & 0.71 & 0.8 & 0.81 \\
Urban concrete surface & 2.40 & 1.7 & 1.3 & 85 \\
\hline
\end{tabular}


value is about $30.3{ }^{\circ} \mathrm{C}$ in this area, and therefore the bottom boundary temperature $\mu_{2}(t) \equiv 30.3{ }^{\circ} \mathrm{C}$. The vertical temperatures of the first day (i.e., on June 1) were employed as the initial temperatures in the numerical simulation. According to Eqs. 1, 2, 3 and the measured data, vertical temperature variations can be simulated in the computer. The simulated temperatures of urban site and suburban site are illustrated with corresponding measured data (points) in Figs. 7 and 8, respectively.

\section{Results and discussion}

\section{Simulation of observed temperature and resultant simulated temperatures}

As shown in Fig. 3a and b, both the observed and simulated temperature indicates a high correlation between
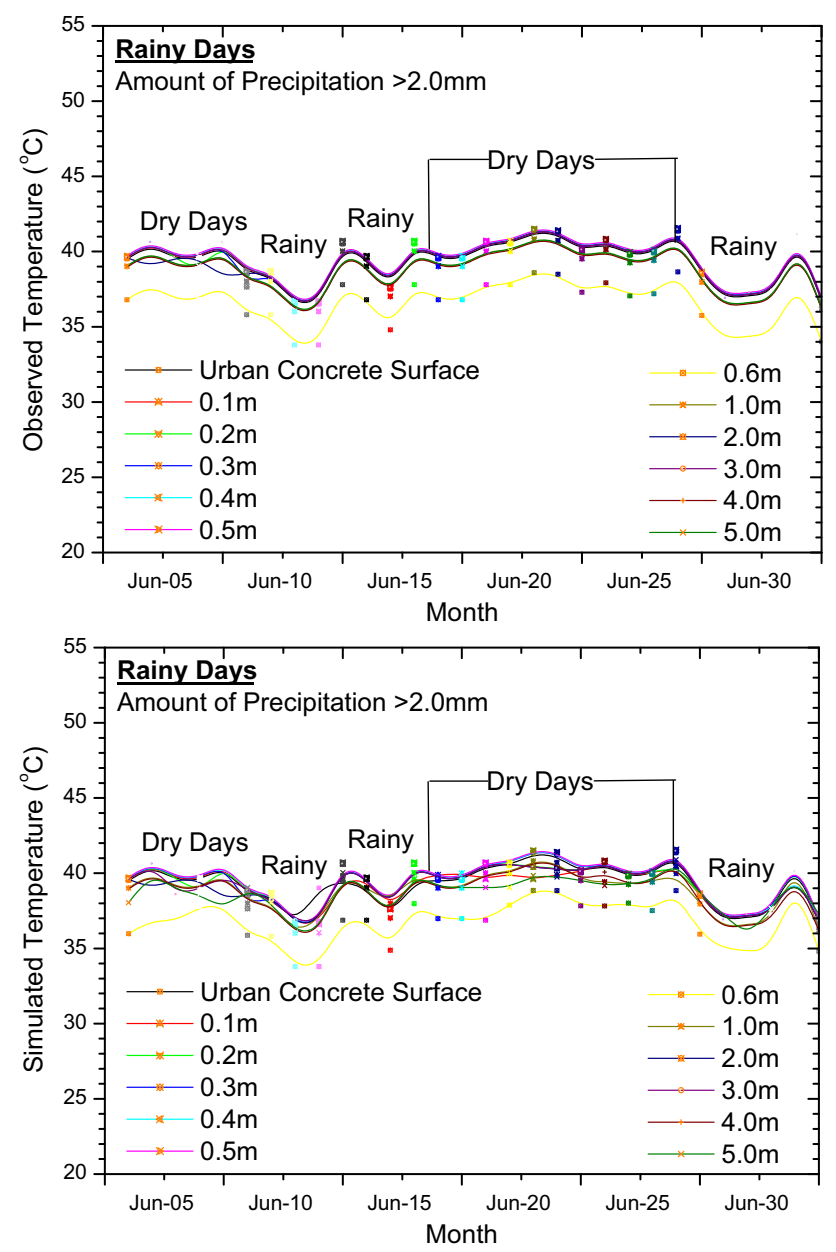

Fig. 7 Observed temperatures at 14:00 $\mathrm{h}$ and simulated temperatures at the heights of $0.1-0.6,1.0,2.0,3.0,4.0$, and $3.0 \mathrm{~m}$ on urban concrete surface vertical air temperatures and surface temperatures. The shallow vertical temperatures fluctuate with the surface temperature, and the amplitude decreases with increasing height. The temperature amplitude is greater for the urban concrete surface in comparison with that of the urban open surface, since both the air temperature amplitude and thermal diffusivity are much greater for urban concrete surfaces. Specifically, the temperature of $0.4 \mathrm{~m}$ fluctuates dramatically in diurnal scale. At the height of $1 \mathrm{~m}$, diurnal temperature change is slight for the urban concrete surface (Fig. 7), and the diurnal temperature influence can be ignored in the case of suburban open surface (Fig. 8). Therefore, the influence of diurnal temperature variation is between 0 and $1 \mathrm{~m}$. At the height of $2 \mathrm{~m}$, diurnal temperature fluctuation has completely disappeared, whereas it is influenced by continuous hot or cool weather, such as a week of hot days in early June. The simulated temperature curves are consistent with the measured temperature points.
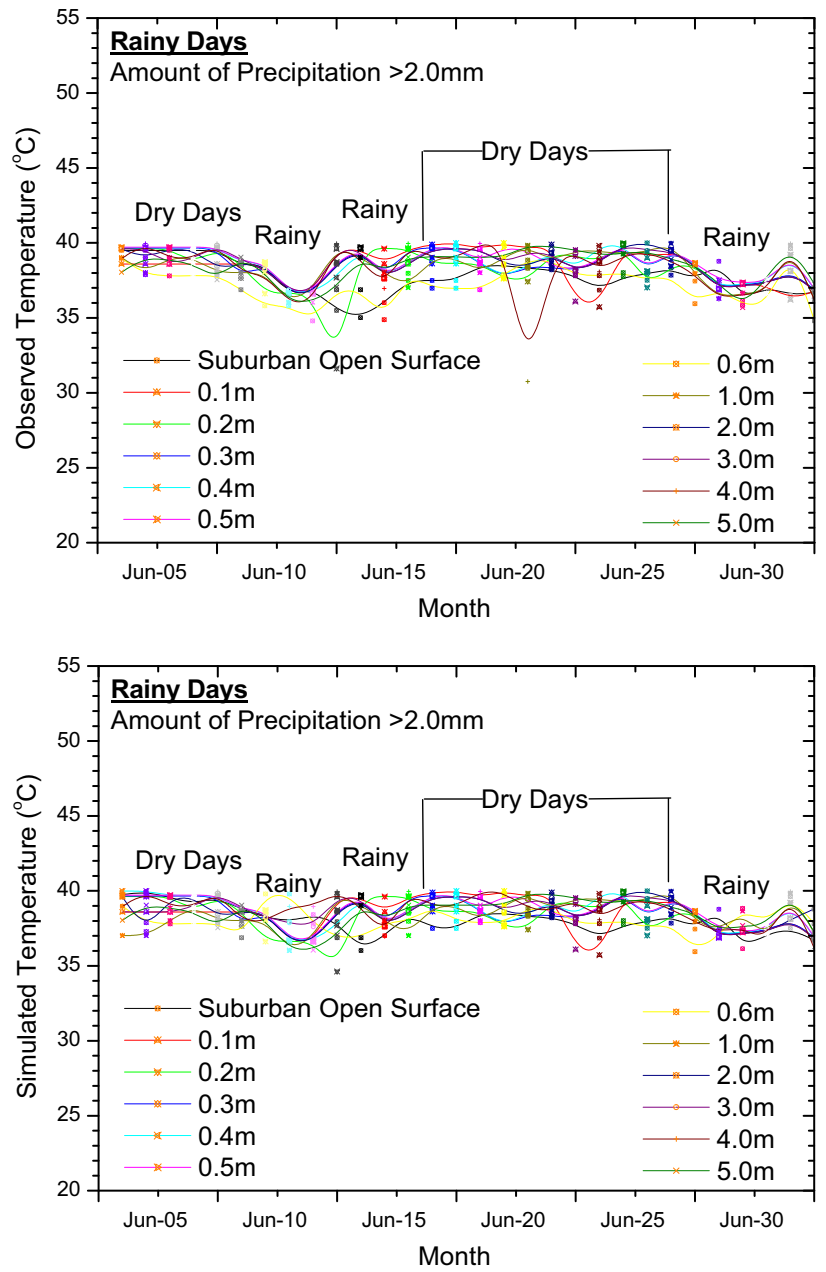

Fig. 8 Observed temperatures at 14:00 $\mathrm{h}$ and simulated temperatures at the heights of $0.1-0.6,1.0,2.0,3.0,4.0$, and $3.0 \mathrm{~m}$ on suburban open surface 
This is especially true in the suburban open site, where the simulated- and measured temperatures share a common trend. Since the air temperatures within $1 \mathrm{~m}$ are influenced by diurnal temperature fluctuation, air temperature deviations between measured data and simulation results are greater in comparison with that of maximum height. In the urban site particularly, influenced by a complex and changing ground environment, the temperature of $0.6 \mathrm{~m}$ level fluctuates dramatically, which may account for the difference from the simulated temperature. However, corresponding temperature also shows similar trend. The simulated temperatures and measured data maintain a high consistency below the height of $1 \mathrm{~m}$ in both the urban and suburban sites. The results show that the method based on high- and lowest air temperatures is practicable.

\section{Surface urban heat island intensity and relative humidity}

The most important phenomenon of urban heat island is that urban air temperature is higher than suburban air temperature.UHI has a major influence on the atmospheric condition, as well as the urban surface environment. The average vertical temperatures of urban concrete surface ( $T_{\text {ucs }}$ ), urban open surface ( $T_{\text {ous }}$ ) and suburban open surface $\left(T_{\text {sos }}\right)$ are shown in Fig. 9. Here, Urban heat island intensity (UHII) is defined as the vertical air temperature difference between urban concrete surface and suburban open surface. As shown in Fig. 9, the total UHII includes environmental UHII $\left(\left(T_{\text {uos }}-T_{\text {sos }}\right)\right.$ and surface UHII $\left(T_{\text {ucs }}-T_{\text {uos }}\right)$ that arise from heat environment and different surface, respectively. In this study, the environmental UHII and the surface UHII are about $2.08{ }^{\circ} \mathrm{C}$ and $2.92{ }^{\circ} \mathrm{C}(4-5 \mathrm{~m}$ height), respectively. Note that the environmental UHII is approximated to the corresponding air UHII Fig. 9.

Owing to long-term continuous heat island effect, the urban surface temperature field increases and air moisture reduces. 'Heat' Islands generally associates with 'Dry' Islands, which means urban air moisture is lower than suburban soil moisture (Shi et al. 2008). As shown in Fig. 9, the urban vertical air temperatures (concrete surface) are greater than the suburban vertical air temperatures, and the average difference is around $2-4{ }^{\circ} \mathrm{C}$. Furthermore, the relative humidity content $(\mathrm{RH})$ under the urban concrete surface and suburban open surface are plotted in Fig. 10a and b, respectively. And the average $R H$ of the urban site is about $85.9 \%$ lower than that of the suburban site. In conclusion, the Urban heat island intensity (UHII) and the urban dry island intensity are about $3.54{ }^{\circ} \mathrm{C}$ and $79.52 \%$, respectively.

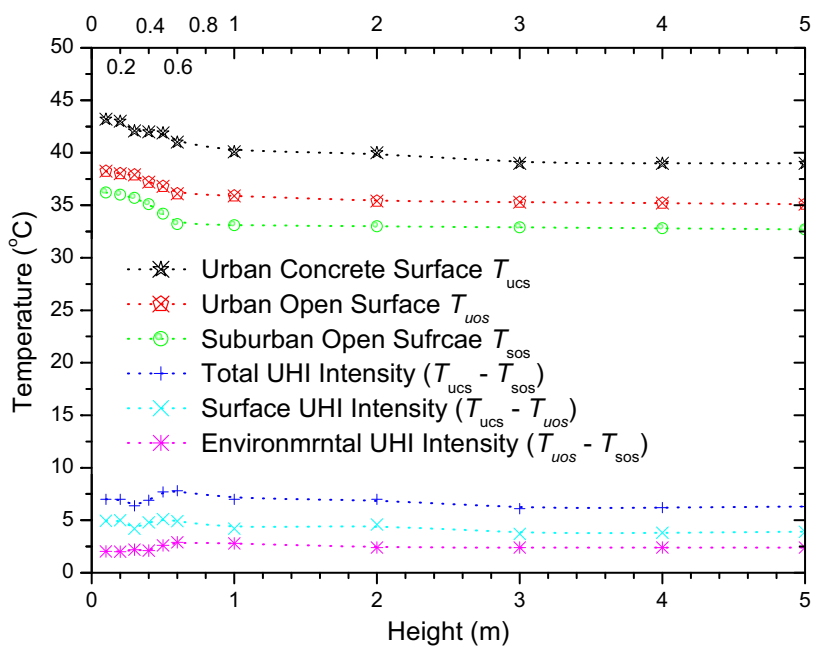

Fig. 9 Average temperatures of three surface types during observation period and Urban heat island intensity (UHII)

\section{Deviation between observed and simulated temperature}

Observed, simulated temperatures are the temperatures under the ideal environment that defined by the model assumptions. However, real vertical air temperatures are influenced by different air moisture, precipitation, sun shine etc., and consequently different from the simulated temperatures. Therefore, the deviation between the Observed temperatures and the simulated temperatures may make available clues for analyzing these influence factors. Figure $11 \mathrm{a}$ and $\mathrm{b}$ show the deviations between simulated and observed temperatures under urban concrete surface and suburban open surface, respectively.

And the corresponding average errors are listed in Table 4, where the average temperature deviations generally decrease with increasing height. The deviation at $0.1 \mathrm{~m}$ is large $\left(2.90{ }^{\circ} \mathrm{C}\right)$ under urban concrete, since it is at the interface between concrete layer and vertical surface. At the heights of $1,2,3,4$, and $5 \mathrm{~m}$, the values are around $0.72{ }^{\circ} \mathrm{C}$, i.e., about $3.22 \%$. These errors are mainly derived from precipitation and humidity variation. Obviously, the variation of relative humidity and urban open surface temperatures leads to changes in air thermal properties. According to Eq. (2), when top and bottom boundary temperatures are given, the vertical air temperatures are essentially determined by air thermal diffusivity $(\alpha)$, which is defined by thermal conductivity $(k)$, air density $(r)$ and specific heat $(c)$ (Eq. 3). These properties are practically unchanged in the specific temperature range of this analysis. However, many previous studies show that thermal conductivity increases with increasing air humidity 


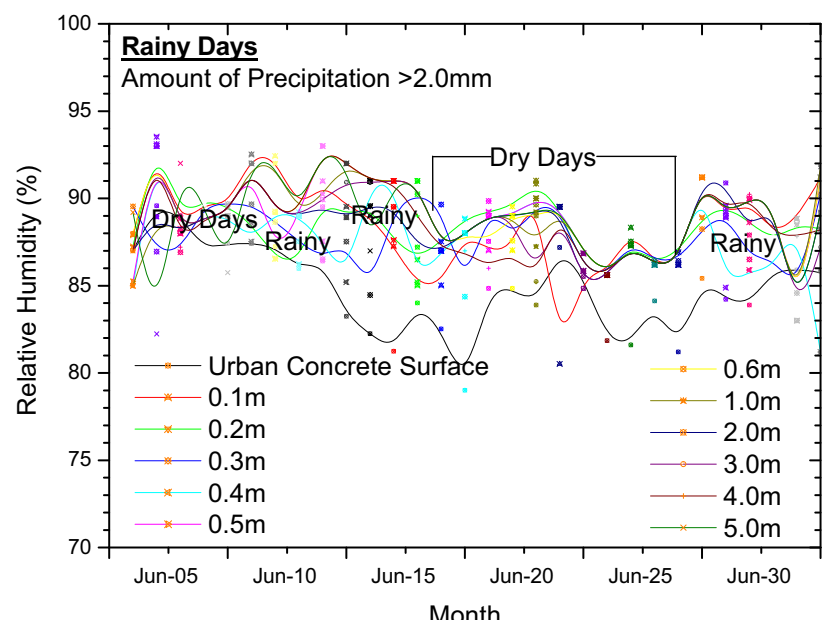

(a)

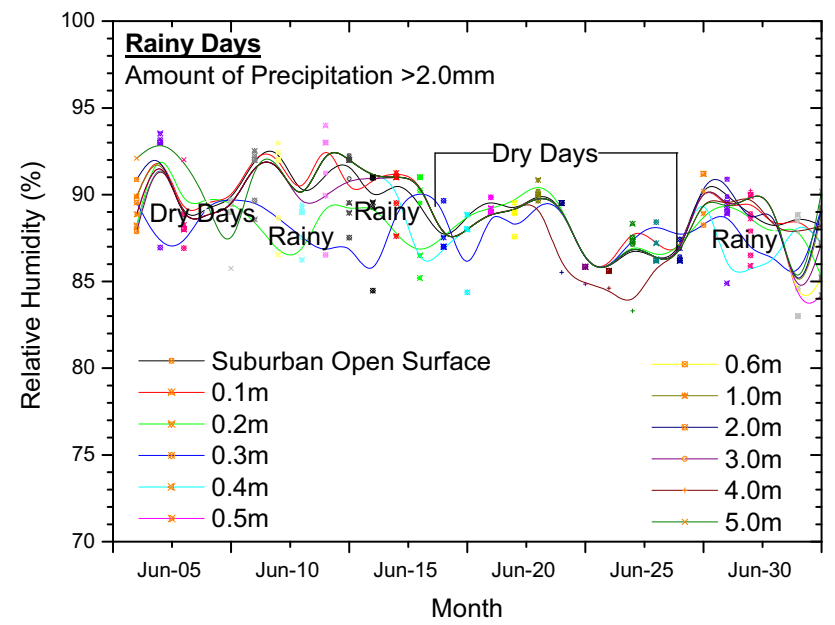

(b)

Fig. 10 Air relative humidity above a urban concrete surface and b suburban open surface

content. Therefore, the variation of the air moisture and the air thermal diffusivity should be taken into consideration. The average air thermal conductivity is used in this study to simulate the variation of vertical air temperature. Air thermal conductivity, however, varies with air relative humidity $(\mathrm{RH})$ in the vertical direction. Shallow layers are generally drier than high layers (Fig. 4a, b), and the thermal diffusivities of shallow layers are therefore lower in comparison with deeper layers. It seems that measured temperatures should be lower than simulated temperatures in the shallow layers $(0.2-0.4 \mathrm{~m})$. However, rainfall and water infiltration reverse this law. Ground surface and the 0-0.4 m layers are cooled due to rainfall (Fig. 11a, b), and at the same time, the surface water is heated by the ground surface. In the case of urban concrete surfaces, most water is dispersed and only a small amount may evaporate into

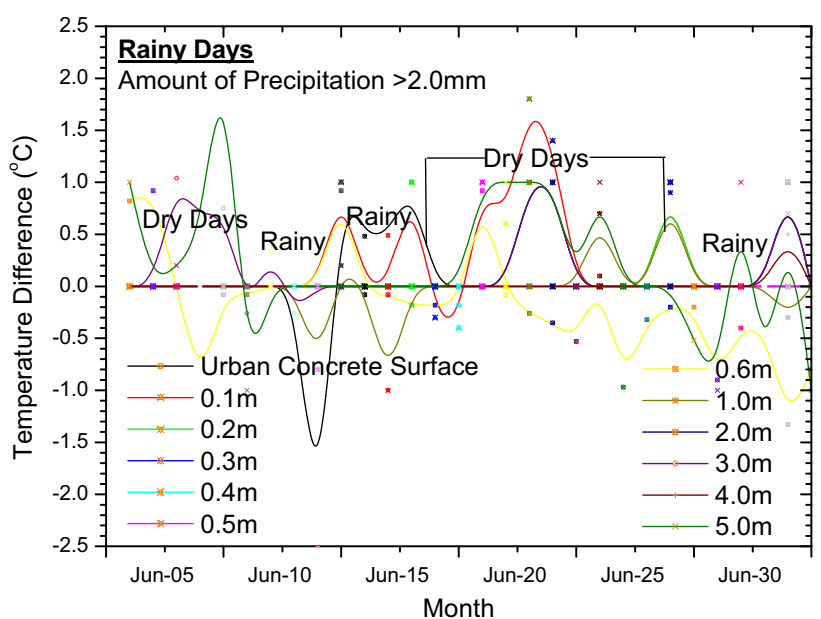

(a)

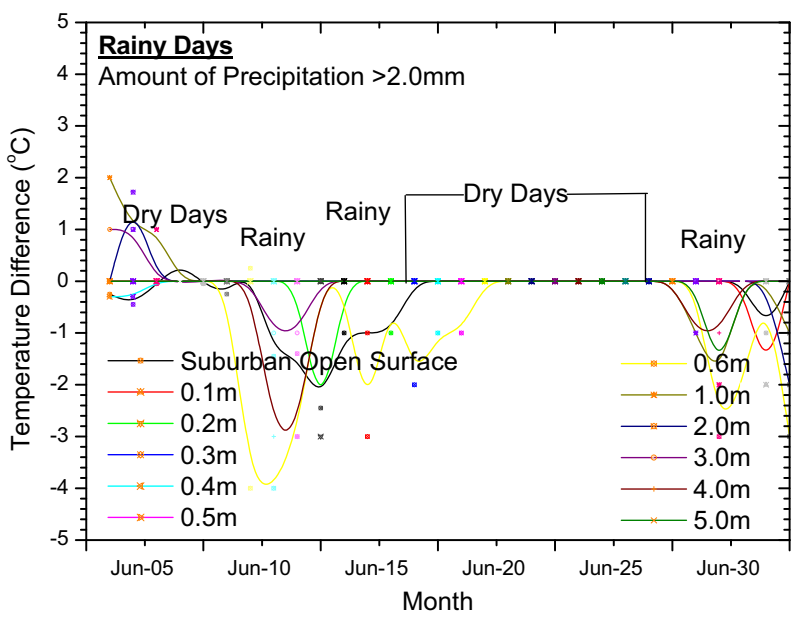

(b)

Fig. 11 Difference between simulated and observed temperatures on urban concrete surface and suburban soil surface

the upper air layer through air ventilation in the concrete. As shown in the relative humidity graph of the urban site (Fig. 11a), there is no obvious relationship between rainfall and relative humidity. However, in the case of the suburban open surface, relative humidity between $1 \mathrm{~m}$ and $4 \mathrm{~m}$ height rises dramatically on rainy days (Fig. 11b), which indicates water evaporate. On the one hand, air moisture increases rapidly and thus air thermal diffusivity rises during the process, i.e. the rate of heat conduction increases. On the other hand, the vertical air is also heated by the sunlight. Therefore, as shown in Fig. 5b, the absolute value of deviation is greater on rainy days (early June and middle June), while the value decreases on dry days (late-June). The phenomenon is more significant at the height of $0.3 \mathrm{~m}$, which is not influenced by diurnal temperature fluctuation. 
Table 4 Mean temperature deviation between simulated and field observations

\begin{tabular}{lllll}
\hline Height $(\mathrm{m})$ & \multicolumn{3}{l}{ Temperature deviation } & \\
\cline { 2 - 5 } & $\begin{array}{l}\text { Urban concrete surface } \\
\text { temperature }\left(T_{\mathrm{ucs}}\right) /{ }^{\circ} \mathrm{C}\end{array}$ & $\begin{array}{l}\text { \% of deviation urban concrete } \\
\text { surface temperature }\left(T_{\text {ucs }}\right) /{ }^{\circ} \mathrm{C}\end{array}$ & $\begin{array}{l}\text { Suburban open } \\
\text { surface }\left(T_{\text {sos }}\right) /{ }^{\circ} \mathrm{C}\end{array}$ & $\begin{array}{l}\% \text { of deviation suburban } \\
\text { open surface }\left(T_{\text {sos }}\right) /{ }^{\circ} \mathrm{C}\end{array}$ \\
\hline 0.1 & 2.90 & 12.98 & 0.77 & 3.44 \\
0.2 & 1.25 & 5.59 & 0.85 & 3.80 \\
0.3 & 1.20 & 5.37 & 0.94 & 4.20 \\
0.4 & 1.02 & 4.56 & 0.88 & 3.94 \\
0.5 & 0.98 & 4.38 & 0.86 & 3.84 \\
0.6 & 0.78 & 3.49 & 0.84 & 3.76 \\
1 & 0.75 & 3.36 & 0.85 & 3.80 \\
2 & 0.74 & 3.31 & 0.73 & 3.27 \\
4 & 0.72 & 3.22 & 0.70 & 3.13 \\
5 & 0.71 & 3.18 & 0.69 & 3.09 \\
\hline
\end{tabular}

\section{Conclusions}

According to the analysis presented above it has been demonstrated that a simplified method is adopted to simulate the variation of vertical air temperatures. By transient heat conduction differential equation and the relationship between air and surface temperatures, only air temperatures at 14:00 h and diurnal lowest air temperatures are required in this model perform. This method was used in the numerical simulation of surface temperatures under urban concrete and suburban open surfaces. The results show that there is good agreement between simulated temperatures and the field observed temperature. The method adopted can be readily applied to estimate vertical air temperatures. Based on the simulation the following conclusions can be drawn:

- According to the measured temperatures, the average temperature under urban concrete surface is $3.54{ }^{\circ} \mathrm{C}$ greater than that of suburban open surface. It is due to the effects of the heat urban environment and different surfaces, which are about $2.08{ }^{\circ} \mathrm{C}$ and $2.92{ }^{\circ} \mathrm{C}$, respectively. Furthermore, the average relative humidity of the urban site is about $79.52 \%$ lower than suburban open surface.

- Relative humidity content also varies in vertical direction, which influences the thermal diffusivity of the surface and the vertical air temperatures. The simulation results indicate that the soil temperature within $0.6 \mathrm{~m}$ is influenced by diurnal temperature fluctuation.

- The average deviation between simulated temperatures and measured temperatures generally decreases with increasing depth. At the heights of 1,2, 3, 4, and $5 \mathrm{~m}$, the the average deviations are around $0.72{ }^{\circ} \mathrm{C}$, i.e., about $3.22 \%$. Rainfall and humidity changes are important factors that result in the deviations.
- Surface types influence on air moisture, which is more significant for the open surface, and therefore, the observed temperatures are greater than simulated temperatures on rainy days.

- The data and the corresponding deviation analysis show that urban heat island, surface types and evaporation have major impacts on vertical air temperatures and air moisture condition. Urban heat island influences both the vertical air temperature field and humidity field, and therefore, changes the engineering properties of urban surface.

Acknowledgments The authors would like to give special thanks for IMD and weatherspark to provide supported micro-meteorological in situ information. Thanks to the anonymous reviewers for their careful review and insightful suggestions which led to a substantial improvement of the original paper.

\section{References}

Akbari H, Bretz S, Kurn DM, Hanford J (1997) Peak power and cooling energy savings of high-albedo roofs. Energy Build 25(2):117-126

Al-Ajmi F, Loveday DL, Hanby VI (2006) The cooling potential of earth-air heat exchangers for domestic buildings in a desert climate. Build Environ 41(3):235-244

Berdahl P, Bretz S (1994) Spectral solar reflectance of various roof materials. In: Cool building and paving materials workshop

Bisai D, Chatterjee S, Khan A (2014a) Detection of recognizing events in lower atmospheric temperature time series (1941-2010) of Midnapore Weather Observatory, West Bengal, India. J Environ Earth Sci 4(3):61-66

Bisai D, Chatterjee S, Khan A, Barman NK (2014b) Long term temperature trend and change point: a statistical approach. Open J Atmos Clim Change 1(1):32-42

Bretz SE, Akbari H (1997) Long-term performance of high-albedo roof coatings. Energy Build 25(2):159-167

Bretz S, Akbari H, Rosenfeld A (1998) Practical issues for using solar-reflective materials to mitigate urban heat islands. Atmos Environ 32(1):95-101 
Chatterjee S, Bisai D, Khan A (2013) Detection of approximate potential trend turning points in temperature time series (1941-2010) for Asansol Weather Observation Station, West Bengal, India. Atmos Clim Sci 4(1):64-69. doi: 10.4236/acs.2014.41009

dos Santos Coelho L, Freire RZ, Dos Santos GH, Mendes N (2009) Identification of temperature and moisture content fields using a combined neural network and clustering method approach. Int Commun Heat Mass Transfer 36(4):304-313

Droulia F, Lykoudis S, Tsiros I, Alvertos N, Akylas E, Garofalakis I (2009) Ground temperature estimations using simplified analytical and semi-empirical approaches. Sol Energy 83(2):211-219

Florides G, Kalogirou S (2007) Ground heat exchangers-a review of systems, models and applications. Renew Energy 32(15): 2461-2478

Graham EA, Lam Y, Yuen EM (2010) Forest understory soil temperatures and heat flux calculated using a Fourier model and scaled using a digital camera. Agric For Meteorol 125(4):640-649

Huang L, Li J, Zhao D, Zhu J (2008a) A fieldwork study on the diurnal changes of urban microclimate in four types of ground cover and urban heat island of Nanjing, China. Build Environ 43(1):7-17

Huang L, Li J, Zhao D, Zhu J (2008b) A fieldwork study on the diurnal changes of urban microclimate in four types of ground cover and urban heat island of Nanjing, China. Build Environ 43(1):7-17

IMD (India Meteorological Department) (2006 \& 2007) Southwest Monsoon-end of season report for 2006 \& IMD, New Delhi. http://www.imd.ernet.in

Jacinto AC, Villar MV, Gómez-Espina R, Ledesma A (2009) Adaptation of the van Genuchten expression to the effects of temperature and density for compacted bentonites. Appl Clay Sci 42(3):575-582

Janssen H, Carmeliet J, Hens H (2004) The influence of soil moisture transfer on building heat loss via the ground. Build Environ 39(7):825-836

Jin MS (2012) Developing an index to measure urban heat island effect using satellite land skin temperature and land cover observations. J Clim 25(18):6193-6201

Khan A, Chatterjee S, Bisai D, Barman NK (2014) Analysis of change point in surface temperature time series using cumulative sum chart and bootstrapping for Asansol Weather Observation Station, West Bengal, India. Am J Clim Change 3:83-94. doi:10. 4236/ajcc.2014.31008

Kolokotroni M, Giannitsaris I, Watkins R (2006) The effect of the London urban heat island on building summer cooling demand and night ventilation strategies. Sol Energy 80(4):383-392

Kondo H, Genchi Y, Kikegawa Y, Ohashi Y, Yoshikado H, Komiyama H (2005) Development of a multi-layer urban canopy model for the analysis of energy consumption in a big city: structure of the urban canopy model and its basic performance. Bound-Layer Meteorol 116(3):395-421

Konopacki S, Akbari H (2001) Measured energy savings and demand reduction from a reflective roof membrane on a large retail store in Austin. Lawrence Berkeley National Laboratory. Berkeley (Report No LBNL-47149)

Kusaka H, Kimura F (2004) Thermal effects of urban canyon structure on the nocturnal heat island: numerical experiment using a mesoscale model coupled with an urban canopy model. J Appl Meteorol 43(12):1899-1910

Liu C, Shi B, Tang C, Gao L (2011) A numerical and field investigation of underground temperatures under Urban heat island. Build Environ 46(5):1205-1210

Mihalakakou G (2002) On estimating soil surface temperature profiles. Energy Build 34(3):251-259

Mirzaei PA, Haghighat F (2010) Approaches to study urban heat island—abilities and limitations. Build Environ 45(10):2192-2201
Mohan M, Kikegawa Y, Gurjar BR, Bhati S, Kandya A, Ogawa K (2012) Urban heat island assessment for a tropical urban airshed in India. Atoms Clim Sci 2(2):127-138. doi:10.4236/acs.2012.22014

Mohan M, Kikegawa Y, Gurjar BR, Bhati S, Kolli NR (2013) Assessment of urban heat island effect for different land use-land cover from micrometeorological measurements and remote sensing data for megacity Delhi. Theor Appl Climatol 112(3-4):647-658

Myrup LO (1969) A numerical model of the urban heat island. J Appl Meteorol 8(6):908-918

Pouloupatis PD, Florides G, Tassou S (2011) Measurements of ground temperatures in Cyprus for ground thermal applications. Renew Energy 36(2):804-814

Rees SW, Adjali MH, Zhou Z, Davies M, Thomas HR (2000) Ground heat transfer effects on the thermal performance of earth-contact structures. Renew Sust Energy Rev 4(3):213-265

Registrar General I (2011) Census of India 2011: provisional population totals-India data sheet. Office of the Registrar General Census Commissioner, India. Indian Census Bureau

Ren GY, Chu ZY, Chen ZH, Ren YY (2007) Implications of temporal change in urban heat island intensity observed at Beijing and Wuhan stations. Geophys Res Lett 34(5):L05711. doi:10.1029/ 2006GL027927

Santamouris M (2015) Regulating the damaged thermostat of the cities-status, impacts and mitigation challenges. Energy Build 91:43-56

Shi B, Liu C, Wang B, Zhao L (2008) Urban heat island effect on engineering properties of soil and the related disaster effect. Adv Earth Sci 23(11):1167-1173

Smerdon JE, Pollack HN, Cermak V, Enz JW, Kresl M, Safanda J, Wehmiller JF (2006) Daily, seasonal, and annual relationships between air and subsurface temperatures. J Geophys Res 111:D07101. doi:10.1029/2004JD005578

Stewart ID (2011) A systematic review and scientific critique of methodology in modern urban heat island literature. Int $\mathbf{J}$ Climatol 31(2):200-217

Synnefa A, Santamouris M, Livada I (2006) A study of the thermal performance of reflective coatings for the urban environment. Sol Energy 80(8):968-981

Synnefa A, Santamouris M, Apostolakis K (2007) On the development, optical properties and thermal performance of cool colored coatings for the urban environment. Sol Energy 81(4):488-497

Taha H, Akbari H, Rosenfeld A, Huang J (1988) Residential cooling loads and the urban heat island-the effects of albedo. Build Environ 23(4):271-283

Tang AM, Cui YJ (2005) Controlling suction by the vapour equilibrium technique at different temperatures and its application in determining the water retention properties of MX80 clay. Can Geotech J 42(1):287-296

Touchaei AG, Wang Y (2015) Characterizing urban heat island in Montreal (Canada) — effect of urban morphology. Sust Cities Soc. doi:10.1016/j.scs.2015.03.005

Wang Y, Akbari H (2015) Development and application of 'thermal radiative power'for urban environmental evaluation. Sust Cities Soc 14:316-322

Weng Q (2009) Thermal infrared remote sensing for urban climate and environmental studies: methods, applications, and trends. ISPRS J Photogramm Remote Sens 64(4):335-344

Yao R, Luo Q, Li B (2011) A simplified mathematical model for urban microclimate simulation. Build Environ 46(1):253-265

Yuan F, Bauer ME (2007) Comparison of impervious surface area and normalized difference vegetation index as indicators of surface urban heat island effects in Landsat imagery. Remote Sens Environ 106(3):375-386

Yuan Y, Ji H, Du Y, Cheng B (2008) Semi-analytical solution for steady-periodic heat transfer of attached underground engineering envelope. Build Environ 43(6):1147-1152 